\title{
Kant, história e a ideia de desenvolvimento moral'
}

\author{
Pauline Kleingeld \\ Professora de Filosofia na Universidade de Groningen, Holanda.
}

Resumo: A filosofia da história de Kant tem sido criticada como sendo incompativel com os principios de sua teoria moral. Para muitos comentadores, a própria ideia de desenvolvimento moral tem sido considerada inconsistente com alguns - ou com todos - os se guintes principios kantianos fundamentais. Em primeiro lugar, sua noção de desenvolvimento racional tem sido considerada incompativel com a afirmação de que a lei moral é incondicional, e assim, universalmente válida (o problema da validade universal). Em segundo, sua noção de desenvolvimento racional, especialmente a noção de 'moralização', parece ir contra a sua tese de que a ação moral é numênica e, assim, atemporal (o problema da atemporalidade). Por fim, a noção de progresso moral parece contradizer a dignidade e a igualdade moral de todos os seres humanos, afirmando que alguns são 'mais livres' que outros (o problema da igualdade moral).Neste artigo, eu argumento que as acusações de inconsistên cia advêm, em grande parte, de uma compreensão insur ficiente do modelo de desenvolvimento racional de Kant. Tomando o problema da validade universal como ponto de partida, eu começo examinando no que consistem 'as disposições para o uso da razãó, e como Kant pensa que elas se desenvolvem no curso da história. Em seguida, eu explico como essa descrição nos permite resolver os dois outros problemas. Termino com a discussão sobre as ra zões de Kant para admitir que existe progresso histórico.

Palavras-chaves: Kant, filosofia da história, desenvolvimento moral, processo de aprendizado.
Abstract: Kant's philosophy of history has been criticized as incompatible with central tenets of his moral theory. To many commentators, the very idea of moral development has seemed inconsistent with some or all of the following basic Kantian tenets. First, his notion of rational development has been said to be incompatible with his claim that the moral law is unconditionally and hence universally valid (the universal validity problem). Second, his notion of rational development, especially the notion of 'moralization', seems to run counter to his thesis that moral agency is noumenal and hence atemporal (the atemporality problem). Finally, the notion of moral progress seems to contradict the dignity and moral equality of all humans by declaring some 'freer' than others (the moral equality problem). In this paper, I argue that the charges of inconsistency stem largely from an insufficient understanding of Kant's model of rational development. Taking the universal validity problem as a point of departure, I start by examining what the 'predispositions for the use of reason' consist in and how Kant thinks they develop over the course of history. I then explain how this account allows us to solve the two other problems. I end with a discussion of Kant's reasons for assuming that there is historical progress.

Key-Words: Kant, philosophy of history, moral development, learning process

1. Originalmente publicado em History of Pbilosopby Quarterly sob o título "Kant, History and the Idea of Moral Development", no volume 16, número 01, janeiro de 1999, p.59-80. Agradecemos a Nicholas Rescher, editor executivo do periódico, por autorizar esta publicação. 
Immanuel Kant defende uma visão teleológica da história. Embora admita que o conhecimento da direção geral da história enquanto um todo é impossível, ele argumenta que nós temos razão para admitir, como princípio regulador, que a história é caracterizada pelo desenvolvimento do potencial racional da humanidade. Em seu ponto de vista, este desenvolvimento racional se manifesta no progresso, não apenas nas artes e nas ciências, mas também na política, educação, religião e moralidade. O desenvolvimento moral deve culminar na "moralização" da humanidade e na transformação da sociedade em um "todo moral".

Contudo, o fato de Kant atribuir apenas um status regulador a essa concepção não o isenta das exigências de consistência conceitual. De fato, apesar de seu status epistêmico fraco, a filosofia da história de Kant tem sido criticada como sendo incompatível com os princípios de sua teoria moral. Para muitos comentadores, a própria ideia de desenvolvimento moral tem sido considerada inconsistente com alguns - ou com todos - os seguintes princípios kantianos fundamentais. Em primeiro lugar, sua noção de desenvolvimento racional tem sido considerada incompatível com a afirmação de que a lei moral é incondicional, e assim, universalmente válida (o problema da validade universal). Em segundo, sua noção de desenvolvimento racional, especialmente a noção de 'moralização', parece ir contra a sua tese de que a ação moral é numênica e, assim, atemporal (o problema da atemporalidade). Por fim, a noção de progresso moral parece contradizer a dignidade e a igualdade moral de todos os seres humanos, afirmando que alguns são 'mais livres' que outros (o problema da igualdade moral).

Embora poucos filósofos compartilhem hoje da visão de Kant sobre a história, a tentativa de responder a estas acusações não deveria ser considerada como uma questão de puro interesse histórico. Se estas acusações não podem ser respondidas, elas colocam em risco a coerência não apenas da filosofia da história de Kant, mas também de sua teoria moral. Dois imperativos centrais da teoria moral de Kant são o comando moral de se esforçar para sua perfeição própria, e o

2. IaG, AA 08:21 e 26 Ver também seção 3. As referências serão dadas de acordo com as abreviações sugeridas para as publicações na Kant-Studien, elencadas na bibliografia. Todas as referências a expressões kantianas e citações de trechos foram extraídas das traduções disponíveis. A paginação das citações mais longas foram indicadas entre parênteses. 
comando de promover o bem supremo, o qual Kant chama de 'mundo moral ${ }^{13}$, 'humanidade sob leis morais's, e uma 'comunidade ética $>^{5}$. Estes imperativos morais devem ser considerados incoerentes se as noções de Kant de desenvolvimento racional e progresso moral contradizem a validade universal da lei moral, a atemporalidade da ação moral, e a igualdade moral de todos os seres humanos ${ }^{6}$. Afinal, esforçar-se para o mundo moral é esforçar-se pelo progresso moral. Se as noções de progresso moral e desenvolvimento racional levam a problemas de inconsistência conceitual, então eles são problemáticos independentemente de Kant falar ou não da realidade ou da possibilidade de tal desenvolvimento e progresso.

Neste artigo, eu argumento que as acusações de inconsistência advêm, em grande parte, de uma compreensão insuficiente do modelo de desenvolvimento racional de Kant . Tomando o problema da validade universal como ponto de partida, eu começo examinando no que consistem 'as disposições para o uso da razão', e como Kant pensa que elas se desenvolvem no curso da história. Em seguida, eu explico como essa descrição nos permite resolver os dois outros problemas. Termino com a discussão sobre as razões de Kant para admitir que existe progresso histórico.

Meu objetivo aqui não é justificar completamente a filosofia da história de Kant. Com efeito, o modelo teleológico pré-Darwinista de Kant é ultrapassado. Além disto, a afirmação de que o comportamento humano está gradativamente se tornando mais moral perdeu toda plausibilidade empírica que Kant pensou que ela ainda possuía. Mas a questão, se Kant pode conceber em absoluto, de modo consis-

3. $\mathrm{KrV} \mathrm{A} \mathrm{808-819/B} \mathrm{836-847.}$

4. KU, AA 05:448 seg.

5. RGV, AA 06:131.

6. Trabalhos recentes mostrando o caráter social do bem supremo em Kant tornaram este problema urgente. Quanto à concepção social do bem supremo, ver Reath, A. "Two Conceptions of the Highest Good in Kant", Journal of the History of Philosopby 26 (1988):593-619; Yovel, Y. Kant and the Pbilosopby. Princeton: Princeton University Press, 1980, 29-80; Anderson-Gold, S. "Kant's Ethical Commonwealth: The Highest Good as a Social Goal", International Pbilosopbical Quarterly 26 (1986): 23-32. Na segunda Crítica, entretanto, a discussão de Kant acerca do bem supremo perde o foco no bem supremo enquanto um mundo em favor de uma abordagem mais orientada ao indivíduo. 
tente, o processo racional, é mais fundamental que a discussão acerca de sua visão específica de história, e é esta questão mais fundamental que importa aqui.

Em prol do foco argumentativo, eu me concentrarei na noção de desenvolvimento racional enquanto tal - especialmente o desenvolvimento moral -, abstraindo de muitos dos detalhes da visão de história de Kant. Permitam-me apenas enfatizar algumas das mais importantes características desta última, a fim de fornecer uma contextualização para a discussão das seções que se seguem ${ }^{7}$. O ingrediente principal da "ideia" reguladora de história de Kant é a concepção de que a natureza (tanto física quanto psicológica) faz com que os seres humanos usem sua razão e exercitem sua liberdade da vontade. Como resultado, os seres humanos desenvolvem suas disposições racionais, o que conduz ao progresso em todas as áreas na qual a razão é empregada, da ciência à política, da moralidade à religião.

Este processo de desenvolvimento não é suave. Na visão de Kant, os humanos têm uma característica psicológica peculiar, que ele chama de "insociável sociabilidade". Esta é uma inclinação mista à interação social $e$ ao isolamento e conflito. O antagonismo social que dela resulta conduz a consequências que são tão danosas que as pessoas sairão do estado de natureza por razões egoístas, e criarão um estado que regulará sua interação de acordo com leis. A mesma dinâmica do egoísmo, por sua vez, levará os Estados, em primeiro lugar, a entrar em guerra, mas depois os levará a buscar estabelecer uma federação internacional para produzir a paz.

Paz, tanto dentro dos próprios Estados quanto entre eles, é a condição sob a qual as disposições da humanidade podem ser mais desenvolvidas, porque a paz fornece um ambiente mais receptivo para o esclarecimento e a educação moral do que a guerra. Para Kant, uma vez que a educação moral for melhorada e o esclarecimento se espalhar para a população em geral, a paz que fora estabelecida a partir do egoísmo e permanecera frágil por causa de sua origem, será finalmente endossada por razões morais e, assim, se tornará duradoura. Deste modo, como resultado da sociável insociabilidade,

7. Ver, Iag AA 08; MAM, AA 08; KU AA 05:§83; ÜGTP, AA 08; ZeF, AA 08. Todavia, o segundo ensaio do Conflito das Faculdades é uma exceção, uma vez que Kant não emprega a noção de desenvolvimento. 
desenvolvem-se aos poucos todos os talentos, forma-se o gosto e tem início, através de um progressivo iluminar-se, a fundação de um modo de pensar que pode transformar, com o tempo, as toscas disposições naturais para o discernimento moral em princípios práticos determinados e assim finalmente transformar um acordo extorquido patologicamente para uma sociedade em um todo moral. ${ }^{8}$

Assim, o desenvolvimento racional deve culminar, por fim, na autotransformação da sociedade em uma comunidade moral ${ }^{9}$.

Kant vê sua concepção teleológica da história confirmada (não provada) pelos fatos. Ele lista o "constante crescimento da liberdade civil" $^{10}$, o "processo regular do melhoramento constitucional em nossa parte do mundo" ${ }^{\prime 11}$ desde os gregos, e chama Frederico, o Grande, de primeiro monarca que "libertou o gênero humano da menoridade ${ }^{\prime \prime \prime 2}$. Ele acredita que sua própria filosofia crítica finalmente colocou a metafísica no caminho de uma ciência progressiva e formulou o verdadeiro princípio da moralidade. Em relação à religião, ele chama sua época de "a melhor" na história, e afirma que a esfera pública está agora esclarecida sobre os princípios da verdadeira fé religiosa, e que nós podemos esperar "uma contínua aproximação à Igreja que une para sempre todos os homens, a qual constitui a representação visível (o

8. IaG, AA 08:21 (p.09).

9. Esta descrição da concepção de história de Kant que eu apresento aqui não é inconteste. Yirmiyahu Yovel e Otfried Höffe argumentaram que a filosofia da história de Kant lida com o progresso jurídico e político, mas não com o moral. Höffe, O. Immanuel Kant. München: Beck, 1983, 244s (tradução brasileira, 270s); Yovel, Y. Kant and the Pbilosopby of History, 127. Ainda que isto seja verdade para parte do segundo ensaio no Conflito das Faculdades (SF, AA 07:92), a evidência dada na nota 02 acima e o final da seção dois mostram que, na grande maioria dos textos sobre história, Kant fala de desenvolvimento moral. Isto é suficiente para o propósito deste artigo. Para uma defesa mais detalhada da minha afirmação de que a visão da história de Kant incluí o progresso moral, ver meu livro, Kleingeld, P. Fortscbritt und Vernunft: Zur Geschichtsphilosopbie Kants. Würzburg: Königshausen und Neumann, 1995

10. $\mathrm{IaG}, \mathrm{AA}$ 08:27.

11. IaG, AA 08:29.

12. WA, AA 08:40. 
esquema) de um reino invisível de Deus sobre a Terra"13 Novos métodos pedagógicos de caráter socrático foram desenvolvidos e, tão logo comecem a ser amplamente utilizados, "a moralidade dos homens bem depressa haverá de melhorar" ${ }^{\prime \prime}$. Kant já pensa que "o gênero humano no seu conjunto progrediu efetivamente e de modo notável sob o ponto de vista moral no nosso tempo, em comparação com todas as épocas anteriores"15

Esta descrição de alguns dos princípios centrais da concepção de história de Kant deve bastar por agora. Conforme forem relevantes, outros detalhes da filosofia da história de Kant surgirão no que se segue.

\section{Desenvolvimento racional e o problema da validade universal}

Ao situá-lo próximo a Hegel, alguns comentadores sugeriram que Kant sustenta que a "razão é historicizada"16, querendo dizer que a própria razão se desenvolve com o tempo. Yirmiyahu Yovel, o maior defensor desta interpretação, também acredita que esta concepção é "insustentável" dentro da estrutura filosófica kantiana. ${ }^{17}$ É fácil entender o por quê. Se a própria razão tivesse que se modificar de qualquer modo significativo, a lei moral também mudaria, já que é o princípio fundamental da razão prática. Entretanto, tal concepção pode ser defendida por Hegel, mas não por Kant. Hegel defende uma visão da história nestes moldes, argumentando que a história inclui um desenvolvimento dialético de diferentes formas "da vida ética". Para Hegel,

13. RGV, AA 06:131-2 (p.154).

14. TP, AA 08:288.

15. TP, AA 08:310 (p. 98).

16. Yovel, Y. Kant ant the Pbilosopby of History, p.4 Yovel desconsidera, em boa parte, os ensaios de Kant sobre história, sustentando que eles são restritos à história política. Ao invés disso, ele desenvolve sua tese da 'história não-empírica da razão' na obra de Kant com base nas três Críticas e na Religião nos limites da simples razão. Sua abordagem hermenêutica o impede de ver que Kant fala, de fato, da história do desenvolvimento das disposições da razão, não do desenvolvimento da razão ela mesma. Isto também explica sua tese segundo a qual Kant não pode construir uma ponte entre sua noção de história da razão e história empírica (p.21).

17. Yovel, Y. Kant and the Pbilosopby of History, p. 271. 
a 'moralidade' kantiana, com sua ênfase em princípios racionais universalmente válidos, não é senão um estágio neste processo, ainda que um estágio elevado. Mas, para Kant, que argumenta que a lei moral é válida de modo universal e normativo - em todos os tempos, em todos os lugares, para todo ser racional -, é impossível conceber diferentes princípios morais e formas de 'vida ética sendo justificadas em diferentes estágios na história. De acordo com Kant, só há um único princípio moral, e a menos "que se queira recusar ao conceito de moralidade toda a verdade (...) não se pode contestar que a sua lei é de tão extensa significação que tem de valer não só para os homens para todos os seres racionais em geral, não só sob condições contingentes e com exceções, mas sim absoluta e necessariamente ${ }^{118}$. Assim, parece que Kant não pode defender de modo consistente a noção de desenvolvimento racional sem abrir mão do validade universal da lei moral.

Argumentarei que o problema da validade universal pode ser resolvido. De acordo com Kant, não é a razão que se desenvolve, mas antes as disposições para o uso da razão. Para compreender adequadamente como esta distinção entre razão e disposições para seu uso fornece a chave para solucionar o problema da validade universal, começo examinando a noção de um desenvolvimento racional das disposições [Anlagen].

Em geral, Kant distingue três modos do uso da razão, com três disposições correspondentes: o uso técnico, o uso prático e o uso moral da razão. A finalidade do desenvolvimento das disposições para estes usos da razão são, respectivamente, a habilidade [Gescbicklicbkeit], a prudência [Klugheit], e a moralidade. O processo de seu desenvolvimento se chama, 'cultivo', 'civilização' e 'educação moral' [moralische Bildung] ou 'moralização' ${ }^{19}$.

$\mathrm{Na}$ concepção de Kant, todas as disposições [Anlagen] em um organismo estão destinadas a um dia se desenvolverem completamente. As disposições humanas para o uso da razão "se desenvolvem" assim como as outras, exceto que seu desenvolvimento leva mais tempo. Diferentemente das disposições físicas, que em princípio podem ser desenvolvidas durante a vida de um indivíduo, as disposições racionais requerem inúmeras gerações para seu completo desenvolvimento. De

\footnotetext{
18. GMS, AA 04:408 (p.41-42).

19. Anth, AA 07:322-24; cp. IaG, AA 08:26.
} 
acordo com Kant, elas podem ser completamente desenvolvidas apenas na espécie, não no indivíduo ${ }^{20}$.

A descrição geral do desenvolvimento enquanto processo teleológico ainda não determina como exatamente deveria ser concebido este processo. Desenvolvimento pode ser concebido tanto como crescimento e fortalecimento, ou como a contínuo emergência de novas estruturas orgânicas, ou qualquer combinação possível destas duas concepções. ${ }^{21} \mathrm{Na}$ Crítica da Razão Pura, Kant adota a primeira concepção. Ele diz que o crescimento de um organismo não ocorre pela adição de "nenhum membro, mas torna cada um deles, sem modificações nas proporções, mais forte e apropriado a seus fins ${ }^{\prime \prime 22}$. A expressão "sem modificações na proporção", em particular, sugere que todos os elementos essenciais já estão aí desde o começo.

Se o desenvolvimento não consiste em nada senão crescimento e fortalecimento, isto tem importantes implicações para a aplicação do conceito de desenvolvimento às disposições para o uso moral da razão. Deste modo, Kant pode defender não uma visão hegeliana do desenvolvimento histórico, mas a visão de que nossas capacidades de julgar e agir moralmente, que estão sempre presentes em uma forma não refinada, são gradativamente melhoradas e fortalecidas.

E é exatamente isto que encontramos em seus textos sobre história. Na Ideia para uma História Universal de um Ponto de Vista Cosmopolita, Kant atribui aos humanos nos primeiros estágios da história não uma disposição para o discernimento moral diferente, mas uma disposição rude e "crua", não cultivada ${ }^{23}$. De modo similar, no Começo Conjectural da História Humana, ele afirma que, no começo da história, os seres humanos compreendiam, "ainda que somente obscuramente" ${ }^{124}$, que eles tinham que ver seus semelhantes como fins.

\section{IaG, AA 08:18.}

21. No final do século 18 essa questão estava sujeita a considerável debate na biologia. Ver McLaughlin, P. Kants Kritik der teleologischen Urteilskraft. Bonn: Bouvier, 1989, 9-31, e Zammito, J. H.The Genesis of Kant's "Critique of Judgment. Chicago: University of Chicago Press, 1992, 189-227.

22. $\mathrm{KrV} \mathrm{A833/B861} \mathrm{(p.600).}$

23. IaG, AA 08:21.

24. MAM, AA 08:114. Cf. Anth, AA 07:324 e KU, AA 05:458. 
Isto não quer dizer que eles também tenham uma compreensão reflexiva correta do princípio da moralidade. Embora Kant pense que as pessoas comuns, através da história, tenham tido um senso basicamente bom - embora não refinado - da obrigação moral, ele também sustenta que a história das tentativas teóricas de teólogos e filósofos de formular o princípio exato e a fundação da moralidade, está repleta de $\operatorname{erros}^{25}$.

Se Kant concebe o desenvolvimento racional como o fortalecimento e melhoramento das faculdades racionais que são as mesmas para todos os seres humanos, sua teoria do desenvolvimento pode estar de acordo com a validade universal da lei moral. Ele acredita que até mesmo os primeiros humanos tiveram uma consciência da obrigação moral que era menos refinada mas estruturalmente similar àquela das gerações posteriores. Baseado na premissa de que todos os humanos têm uma consciência moral que é estruturalmente similar, a análise que Kant faz da consciência da obrigação moral na Crítica da Razão Prática se aplica de maneira uniforme a todos os humanos, não importando seu nível de desenvolvimento.

\section{Desenvolvimento e o problema da igualdade moral}

Embora Kant não acredite que a razão ela mesma se modifique, ainda é possível pensar que sua teoria moral é comprometida pela concepção de acordo com a qual as disposições racionais dos seres humanos se modificam. Se assim fosse, gerações anteriores poderiam parecer menos completamente humanas do que as posteriores. Pois, ainda que todos os humanos sejam capazes de agir moralmente, o desenvolvimento das disposições pareceria implicar que eles não são igualmente capazes. Porém, se fosse este o caso, isto ameaçaria a igualdade moral dos seres humanos. Se estes não são, em absoluto, igualmente capazes de agir moralmente, eles não podem ter a mesma capacidade moral.

De fato, Kant sustenta justamente esta visão quando ele compara homens e mulheres ${ }^{26}$. Ele considera as mulheres como um tipo

25. GMS, AA 04:403-404 e 411.

26. Ver, por exemplo, "Das fraquezas da mente na faculdade de conhecer", Anth, AA 07:208-212 e "O caráter do sexo" Anth AA 07:303-311. Eu discuto as tensões entre o uso que Kant faz do termo de gênero neutro "ser humano" [Mensch] e suas observações específicas sobre as mulheres em meu artigo 
anormal de ser humano cuja disposição moral nunca se desenvolve completamente, e cuja perpétua imaturidade justifica uma condição permanente de tutela. Todavia, seus argumentos para justificar a desigualdade das mulheres estão em flagrante contradição com sua teoria geral sobre os "humanos" e são notoriamente fracos. Para os propósitos da minha argumentação, a questão é se ele sustenta, em relação às gerações anteriores, uma concepção não-igualitária igualmente problemática.

Esta questão nos leva à teoria de Kant da herança biológica. Pois, se este 'desenvolvimento das disposições na espécie' [Anlagen der Gattung] significa que os humanos de diferentes épocas têm diferentes disposiçôes, isto implicaria a diferença do seu status moral. Pois, se algumas gerações entram no mundo com faculdades morais mais superiormente desenvolvidas do que outras, isto pareceria implicar que algumas gerações são mais aptas para reconhecer e obedecer os comandos morais do que outras. Contudo, como veremos, Kant tem uma teoria biológica segundo a qual é possível dizer que todos os seres humanos de todas as épocas ${ }^{27}$ podem ser vistos como compartilhando as mesmíssimas disposições.

Kant defende a teoria da preformação genérica (ou 'teoria da epigênese'). Admitindo que a concepção de que a vida emerge da matéria sem vida é "contrária à razão" 28 , e rejeitando o ocasionalismo e a formação pré-individual por darem um papel muito importante para Deus $^{29}$, Kant opta pela concepção de que Deus simplesmente "preformou" a espécie dos organismos quando criou o mundo, dando a cada

"The Problematic Status of Gender-Neutral Language in the History of Philosophy: The Case of Kant", Philosopbical Forum 25 (1993): 134-150.

27. É preciso ter em mente, contudo, a tensão entre esta concepção e suas concepções sobre as mulheres. O mesmo se aplica à noção de raça em Kant. Embora sua teoria de raça oficial seja posta estritamente em termos de cor de pele, os argumentos de Kant ocasionalmente deterioram-se em argumentos racistas no que tange a capacidades mentais, ver, por exemplo, ÜGTP, AA 08:175-6.

28. KU, AA 05:424. Observações similares se encontram já em 1762. Ver McLaughlin, Kants Kritik der teleologischen Urteilskraft, p.26.

29. De acordo com o ocasionalismo, Deus intervém em cada criação para dar à matéria sua forma orgânica. De acordo com a teoria da pré-formação, Deus criou os "germens" para cada organismo individual de uma só vez, e todos estes organismos-miniaturas estão guardados à maneira de bonecas russas, 
uma suas disposições, que permitiram, subsequentemente, a cada espécie se desenvolver e reproduzir por si própria ${ }^{30}$. Assim, a atividade "original de organização" de Deus não se estende a todo e qualquer organismo individual, mas somente aos primeiros exemplares de cada espécie. Depois da criação, a natureza faz tudo por si só.

Kant também acredita que, após a criação, as disposições essenciais com as quais os membros de uma espécie nascem não se alteram. Influências externas podem modificar o desenvolvimento dos indivíduos e explicar diferenças entre exemplares da mesma espécie, mas elas não podem produzir uma mudança nas qualidades essenciais que são herdáveis. As disposições essenciais dadas a cada espécie na criação são todas herdadas. ${ }^{31}$

Ainda que por vezes Kant admita algum progresso no desenvolvimento de uma disposição a ser transmitida biologicamente para gerações posteriores, ele não acredita que seja este o caso das disposições racionais. Em relação à cor da pele, ele lança a hipótese de que as gerações posteriores nascem em um estágio mais desenvolvido. Ele defende a hipótese de que houve uma vez uma espécie originária [Stammgattung] que continha, não desenvolvidas, disposições para diferentes cores de pele. Depois que os seres humanos se espalharam pela face da terra, as disposições se desenvolveram de acordo com as exigências postas pelos diferentes climas, levando a tons de peles cada vez mais diversificados. ${ }^{32}$ Ele está claramente comprometido com um processo multigeracional de desenvolvimento, cujos resultados são herdados. Não obstante, em relação às faculdades humanas racionais, Kant não concebe o desenvolvimento deste modo. Ele justifica isso referindo-se simplesmente ao fato de que nenhuma evidência empírica sustenta tal concepção ${ }^{33}$. Gerações posteriores não entram neste mundo em um estado no qual elas te-

esperando o tempo para seu posterior desenvolvimento. Cf. KU AA 05: 422-3.

30. KU, AA 05:424.

31. MAM, AA 08:110 (p.111): "pois se fossem inatas [estas habilidades] seriam também hereditárias".

32. BBMR, AA 08:105. Criando uma tensão com sua própria visão geral que as disposições não se alteram, Kant especula que as disposições originais para as outras cores de pele devem ter subsequentemente desaparecido.

33. MAM, AA 08:110ss. 
nham desenvolvido mais sua habilidade para utilizar a razão do que qualquer das gerações anteriores.

O resultado disto é que os seres humanos de todas as épocas entram no mundo com exatamente as mesmas disposições racionais. Esta conclusão apresenta nítidas vantagens à luz da teoria moral de Kant, e esta pode ter sido outra razão pela qual ele a endossa. Se tivesse concebido o desenvolvimento das disposições racionais em analogia com o desenvolvimento da cor de pele, ele teria que ter considerado os seres humanos de diferentes épocas (e, talvez, seres humanos de diferentes culturas, ou alguma outra diferença no 'ambiente' moral análoga ao clima), como tendo um potencial moral cada vez mais diverso.

\section{Desenvolvimento como processo de aprendizagem}

Dada a visão de Kant de que essas disposições elas mesmas não se alteram com o curso das gerações, surge a questão: o que significa dizer que elas se desenvolvem com o tempo? Se gerações posteriores não vêm ao mundo em um estado mais desenvolvido, como é possível que o desenvolvimento das disposições racionais aconteça?

Kant argumenta que o desenvolvimento das faculdades humanas racionais é um processo de aprendizagem. Os resultados deste processo são transmitidos para as próximas gerações não de modo biológico, mas pedagógico, mediado por instituições pedagógicas, bem como sociais e culturais. Cada indivíduo, e cada geração "começa novamente do $\mathrm{ABC}$ e tem de atravessar toda a distância já percorrida" ${ }^{134}$. Embora não seja verdadeiro em sentido literal que os indivíduos tenham que refazer todos os passos já feitos anteriormente, indivíduos de gerações posteriores têm que se apropriar das habilidades e do conhecimento adquirido pelas gerações prévias. Somente então eles estarão em condições de adicionar um passo ${ }^{35}$.

Neste processo histórico, os seres humanos aprendem, por exemplo, como defender-se de perigos naturais. Eles também aprendem que é mutuamente vantajoso submeter-se a leis, tanto no nível nacio-

34. MAM, AA 08:117 n.,/trad.118, cf. Anth, AA 07:325ss.

35. Assim, a ontogênese recapitula a filogênese, e ambos os processos têm a mesma estrutura. Sobre a ontogênese, ver Päd, AA 09:449seg., 455seg., 486ss.; sobre filogênese, ver IaG, AA 08:26; Anth, AA 07:322ss.; Päd, AA 09:451. 
nal quanto internacional. Kant sugere, como uma perspectiva para o futuro, que, uma vez que haja paz, ainda que seja alcançada por meio do mero egoísmo, as pessoas podem e irão canalizar as energias que foram usadas para a guerra, para melhores causas, o que leva a um maior desenvolvimento racional. Assim, ele afirma que a paz é a precondição para o desenvolvimento total de todas as disposições humanas ${ }^{36}$

Aqui a educação tem um papel crucial. Ela também se desenvolve na história, o que dá ao processo de aprendizagem histórico uma qualidade cumulativa e de auto-reforço. Na Pedagogia e na Crítica da Razão Prática, Kant afirma que a Ilustração produziu, pela primeira vez na história, métodos pedagógicos que encorajam as crianças a pensar por si mesmas e a serem moralmente autônomas. Os métodos antigos, autoritários, tinham em vista produzir a obediência cega, levando principalmente a um comportamento guiado pela inclinação para evitar punições e ganhar recompensas. Os novos métodos têm uma abordagem socrática, maiêutica, e Kant desenvolve sua própria versão de um método na Doutrina do Método da Crítica da Razão Prática. É evidente que professores não podem causar nos seus alunos uma disposição moral, mas eles podem fazer muito para ajudá-los a sentirem seu próprio valor e reconhecer aquilo que o dever exige. Assim, os alunos se tornam conscientes de sua própria vocação moral e isso "confere ao ânimo [do aluno] uma força, não esperada por ele mesmo de libertar-se de todo apego sensível ${ }^{\prime \prime 37}$ e agir moralmente. Kant considera este novo método pedagógico a chave para o progresso mora ${ }^{\beta 8}$. Uma vez estabelecidas a paz, a liberdade e melhorada a educação moral, as precondições estão dadas para que os seres humanos transformem a sociedade de uma ordem meramente legal, inicialmente estabelecida com base nas inclinações, num 'todo moral'. Kant não afirma que este estado ideal será alguma vez completamente realizado, mas argumenta que podemos nos aproximar dele.

A avaliação de Kant da situação em sua própria época é assim expressada na Ideia: "Mediante a arte e a ciência, somos cultivados em alto grau. Somo civilizados até a saturação [bis zum Überlastigen] por toda espécie de boas maneiras e decoro sociais. Mas ainda falta muito

\footnotetext{
36. $\mathrm{IaG}, \mathrm{AA}$ 08:23 e 25 .

37. $\mathrm{KpV}, \mathrm{AA} 05: 152$ (p.241)

38. Päd, AA 09:441 e 444; KpV, AA 05:153; cf. também TP, AA 08:288.
} 
para nos considerarmos moralizados. ${ }^{\prime 39}$ Não obstante, algum progresso moral foi feito, e em ensaios posteriores ele afirma que a humanidade já progrediu por diversos estágios de moralidade [Stufen der Sittlicbkeit] e também que "nossa época" é moralmente superior às anteriores ${ }^{40}$. Sua crença no poder da educação tem um papel importante neste otimismo.

Contudo, a caracterização de Kant da história como um processo de aprendizagem leva a duas novas questões. A primeira é se esta caracterização pode ser reconciliada com a atemporalidade da ação numênica (o problema da atemporalidade). A segunda é se esta concepção de história como processo de aprendizagem não conduz a outra versão do problema da igualdade. Começo com a primeira questão.

\section{Aprendizado moral e o problema da atemporalidade.}

Alguns autores argumentaram que a concepção de história de Kant como um processo de aprendizagem não soluciona a tensão entre sua filosofia moral e sua filosofia da história. Michel Despland formulou a acusação do seguinte modo:

Razão, autonomia e moralidade são apresentadas na filosofia da história como surgindo dentro de um processo, enquanto as leis do uso prático da razão, ou as leis da moralidade, são deduzidas transcendentalmente na segunda Crítica e são consideradas a priori, portanto, está implicado que elas estão acima do processo do temporal e são "eternamente válidas" (...). A filosofia da história (...) mina a distinção entre objetivamente prático e subjetivamente prático. A filosofia da história mostra que a lei moral "objetiva" foi "subjetivamente" aprendida pela raça, ou por alguns membros dela, apenas em algum período do processo da história...Mas este ponto de vista na filosofia da história torna a moralidade algo inserido no processo histórico, por exemplo, como relacionada à experiência histórica (...) e isto não parece estar senão em tensão com o ponto de vista assaz atemporal da Crítica da Razão Prática. ${ }^{41}$

39. IaG, AA 08:26; cf. Päd, AA 09:451.

40. TP, AA 08:310; EAD, AA 08:332.

41. Despland, M. Kant on History and Religion. Montreal: Mc Gill-Queen's University Press, 1973, p.67s. 
De acordo com Despland, Kant não pode ter tudo: a moralidade não pode ser válida a priori e ao mesmo tempo o resultado de um processo de aprendizagem histórico.

Entretanto, se formulado do seguinte modo, a tensão entre "atemporal" e "histórico" pode ser facilmente dissolvida. A acusação de uma contradição proposital se apoia numa falha em distinguir entre a criação e a descoberta do princípio moral. Ao dizer que a história é um processo de aprendizagem no qual uma tosca capacidade para o discernimento moral se desenvolve até alcançar uma outra refinada, Kant não está afirmando que as exigências morais são criadas em uma determinada época da história mas, antes, que elas vêm a ser completamente compreendidas de modo gradual. Esta é uma distinção plausível de se estabelecer. $\mathrm{O}$ fato de que não se compreende totalmente algo de modo imediato, mas tem que se aprendê-lo, não significa que isto não fosse válido antes de ser aprendido. De modo análogo, o fato de que uma nítida compreensão da moralidade enquanto autonomia é o resultado de um longo processo de aprendizagem histórico não é por si só incompatível com a validade absoluta e atemporal da lei moral. Para Kant, a validade normativa da lei moral não depende do fato de ser subjetivamente reconhecida como tal. Inversamente, o que é objetivamente válido não se torna menos válido se é aprendido (subjetivamente) apenas em determinada época da história. Assim, a filosofia da história de Kant não borra a distinção entre 'objetivo' e 'subjetivo'.

Kant aponta para isto em um contexto diferente, a saber, na discussão do sublime na Crítica do Juízo. Ele diz: "o juízo sobre o sublime da natureza. Embora necessite de cultura (...) nem por isso foi primeiro precisamente produzido pela cultura e como que introduzido simplesmente por convenção na sociedade ${ }^{\prime \prime 4}$. De modo similar, o fato de que o julgamento moral requer algum desenvolvimento histórico ('cultura'), não implica que ele seja gerado por esse processo e introduzido na sociedade por simples convenção. Na visão de Kant, do contrário, ele é fundado na razão.

Uma observação paralela pode ser feita em relação ao próprio projeto filosófico de Kant. Kant situa seu próprio projeto historicamente, como o produto de um longo desenvolvimento ${ }^{43}$. Ele afirma que sua filosofia transcendental explica de modo definitivo os princí-

42. KU, AA 05:265 (pp. 111-112).

43. Por exemplo, em KrV A852-856/B880-884 e em ZeF, AA 08. 
pios que as pessoas sempre tiveram em mente de modo vago. Mas, ao formular o verdadeiro princípio da moralidade de um modo filosoficamente rigoroso pela primeira vez na história - Kant afirma nada menos do que isso -, ele não transforma a moralidade em algo contingente e "simplesmente introduzido por convenção". Na segunda Crítica, por exemplo, Kant insiste que ele não está apresentando um princípio de moralidade completamente novo. Ao invés disto, ele compara a sua derivação do imperativo categórico a uma derivação matemática de uma fórmula ${ }^{44}$. Para Kant, ao contrário de Hegel, não é a moralidade que precisa passar por um processo histórico, mas a nossa compreensão dela.

Estas considerações não apenas fazem com que seja possível responder às objeções de Despland, como também mostram que Kant não deveria ser interpretado como querendo somente desenvolver um princípio moral "para seu próprio tempo", como pareceria ter sugerido Allen Wood. Wood afirma que "não há nada a-histórico na ética kantiana. Ela tem uma compreensão de si mesma historicamente situada, e é dirigida a necessidades culturais específicas de sua própria época ${ }^{145}$. É nítido que Wood está certo ao dizer que Kant tem um entendimento de seu projeto que é historicamente situado. Mas ele dificilmente pode querer dizer que Kant torna a moralidade historicamente relativa, já que isto iria contra a afirmação de Kant de que a lei moral é incondicionalmente válida e contra sua própria interpretação perspicaz da obra de Kant. Mas, se a reivindicação de Kant da validade incondicional deve ser levada a sério, devemos reconhecer que há algo de a-histórico na filosofia da história de Kant.

Ao elevar a absoluta validade do princípio moral acima da contingência histórica, Kant dá a sua filosofia da história um núcleo a-histórico. O princípio moral não vem à existência em um certo período - neste sentido, ele é, sem dúvida, atemporal. Ele 'somente' se torna mais nítido com o tempo. Ele é e sempre foi objetivamente válido, uma vez que é fundado na razão, mas apenas gradualmente reconhecido subjetivamente e compreendido como tal.

A reivindicação de Kant da absoluta validade da lei moral é, sem dúvida, muito contestada no debate filosófico atual. Para os presentes

44. KpV, AA 05:8n.

45. Wood, A. "Unsocial Sociability: The Anthropological Basis of Kantian Ethics", Pbilosopbical Topics 19 (1991): 325-351, p.336. 
propósitos, entretanto, a questão principal é que essa reivindicação é compatível com a noção de desenvolvimento moral, enquanto se conceba este desenvolvimento como um processo de aprendizagem.

\section{Moralização e a atemporalidade da ação numênica}

Neste ponto, alguém poderia objetar que o argumento da seção quatro se aplica somente ao desenvolvimento do insight do que é moralmente requerido, mas os problemas reais começam com a afirmação de Kant de que há um aumento do comportamento moral. Kant raras vezes discute esse tipo de progresso. De fato, ele é mais bem conhecido por procurar fragilizar o sentimento de superioridade moral de seus contemporâneos, invocando, por exemplo, o sombrio diagnóstico do "observador de sangue-frio" no começo da segunda parte da Fundamentação da Metafísica dos Costumes ${ }^{46}$. Mas, como vimos na seção três, Kant certamente sustenta a perspectiva de um progresso moral para o futuro, e algumas vezes sugere mesmo que algum progresso já foi feito.

Essa noção do progresso moral evoca toda uma série de questões relacionadas ao fato de que, na discussão da terceira antinomia na Crítica da Razão Pura, Kant argumenta que a ação moral é numênica, e assim não apenas atemporal, como também não cognoscível. Isto parece tornar duplamente problemática a afirmação de que a capacidade e a resolução dos seres humanos de agir moralmente aumenta com o tempo. Pelo fato de a disposição moral [Gesinnung] do agente ser numênica, um insight em qualquer dos melhoramentos em sua qualidade é impossível. E porque essa disposição moral é numênica, ela é atemporal, o que pareceria tornar sem sentido falar que ela sofra mudanças através da história. Assim, a terceira antinomia pareceria proibir Kant de falar em um crescimento do comportamento moral.

Contudo, Kant nos mostra um caminho no qual podemos pensar e falar sobre disposições morais. Primeiramente, ele não reivindica o status de conhecimento para sua afirmação sobre o aumento da moralidade. Muitos de seus textos sobre história começam com a afirmação de que nós não podemos obter conhecimento do curso da história como um todo ${ }^{47}$. E na introdução à Ideia para uma

\footnotetext{
46. GMS, AA 04:407.

47. Por exemplo em TP, AA 08:307-8 e SF, AA 07:83.
} 
História Universal ele deixa claro que sua visão de progresso deveria ser compreendida enquanto uma ideia reguladora com propósitos heurísticos. Ainda depois de ter mostrado exemplos que pareceriam confirmar sua visão da história, ele afirma que a ideia é "útil", não que é verdadeira. ${ }^{48}$

Além disto, na primeira Crítica, ele explica que, embora nós não possamos conhecer o caráter da disposição moral numênica de um agente, nós podemos, contudo, "pensá-la" como estando "de acordo com" o caráter empírico do agente. E podemos conceber o caráter empírico com base nas ações do agente ${ }^{49}$. Esta mudança do nível empírico para o numênico - em pensamento, não no conhecimento - é o que subjaz na nossa própria prática de desprezo e elogio moral. Pois, se eu acuso alguém de comportamento imoral, tudo aquilo no qual posso me basear são as ações desta pessoa enquanto aparências. As afirmações de Kant sobre o aperfeiçoamento moral na história podem ser interpretadas de modo análogo, como se referindo meramente a como nós concebemos a disposição moral das gerações futuras, com base nas ações manifestas, dadas ou mesmo esperadas ${ }^{50}$.

Em um nível mais profundo, a noção de Kant de aperfeiçoamento moral se depara com outro problema, a saber, como sequer 'pensar' uma mudança num caráter moral atemporal. O próprio conceito de mudança parece implicar a temporalidade. Kant reconhece ele mesmo que a possibilidade da mudança numenal é, sem dúvida, incompreensível. Mas, ele diz, para os propósitos morais nós temos que conside-

48. IaG, AA 08:29. Isto parece ser contradito pela fala de Kant sobre as 'provas'de progresso em "Teoria e Práxis" (TP, AA 08:310) Contudo, dado que todo o argumento de Kant neste ensaio tem como premissa a impossibilidade de qualquer prova teórica, e dado que ele argumenta pelo progresso em bases morais, o termo 'prova' deve ser interpretado em um sentido mais fraco do que aquele de uma prova teórica. Kant também emprega um sentido fraco do termo prova na frase "prova moral da existência de Deus" no §87 da Crítica do Juízo.

49. $\mathrm{KrV} \mathrm{A540/B568.}$

50. Ocasionalmente isto é negado pelo próprio Kant, ao dizer que, caso se olhe para o comportamento dos outros, se concluirá que somente o egoísmo os motiva (por exemplo em GMS, AA 04:453 e SF, AA 07:91-2). Como recentemente notou Christine Korsgaard, seu argumento não é válido. Cf. Korsgaard, C. Creating the Kingdom of Ends. Cambridge: Cambridge University Press, 1996, p. 210. 
rá-la como possível ${ }^{51}$. Aqui ele recai em seu argumento de que nada pode ser conhecido do caráter numênico e admite que, ainda que nada possa ser conhecido dele, não há razão para excluir a possibilidade do aperfeiçoamento moral, ainda que nossas faculdades cognitivas sejam inadequadas para compreendê-lo.

\section{O problema da igualdade revisitado}

Talvez a crítica mais frequentemente direcionada contra a filosofia da história de Kant seja a de que a noção de aperfeiçoamento moral é conflitante com a ideia da igualdade e dignidade de todos os seres humanos. Emil Fackenheim criticou Kant por fazer das "livres realizações de uns [o] meio para as realizações ainda mais livres de outros $^{\prime \prime 52}$. Ele vê um duplo problema para a igualdade moral. Primeiramente, se Kant diz que os humanos se tornam gradativamente mais livres no curso da história, e que as primeiras gerações transmitem seu insight para as posteriores, ele é forçado a qualificar o conceito de liberdade historicamente. Mas isto é inconsistente com o fato de Kant chamar todo agente humano de livre sem qualificações. Em segundo lugar, uma vez que as primeiras gerações transmitem o seu insight para as gerações posteriores sem estarem elas mesmas completamente capazes de agir moralmente, isto reduz as primeiras gerações a meros meios para o progresso do qual as gerações posteriores se beneficiam ${ }^{53}$.

Os méritos da objeção de Fackenheim dependem fundamentalmente do fato de a noção de progresso moral acarretar, ou não, que devamos considerar os agentes do passado como menos livres. Mas Kant nega isto. Como vimos na seção dois, mesmo os primeiros seres humanos são considerados como sendo totalmente livres, tendo a habilidade de agir moralmente, e tendo, em geral, um sentido correto do que é certo ou errado.

51. RGV, AA 06:44-53.

52. Fackenheim, E. L. "Kant's Concept of History", Kant-Studien 48 (1956-57), p. 397.

53. Ver também Galston, W. A. Kant and the Problem of History. Chicago: University of Chicago Press, 1975, pp.231ss.; Stern, P. "The Problem of History and Temporality in Kantian Ethics", Review of Metaphysics 39 (1986): 505-545 
Mas esta resposta parece trocar uma versão do problema da igualdade moral por outra. Pois a noção de progresso moral, junto com o afirmação de que as gerações passadas não eram em nada menos livres do que as mais desenvolvidas, obriga Kant a dizer que as gerações anteriores são mais condenáveis moralmente do que as posteriores. Isto está simplesmente implicado na sua fala acerca do progresso moral. Mas as gerações posteriores se beneficiam das realizações das anteriores. Uma vez que a história é um processo de aprendizagem, uma compreensão moral mais nítida e uma educação moral melhorada capacitam as gerações posteriores a levar uma vida mais virtuosa do que as primeiras. Deste modo, pode-se querer reformular a objeção de Fackenheim e acusar que é injusto condenar as primeiras gerações que não têm a vantagem educacional e que não podem evitar falhar em comparação com as posteriores.

É preciso apontar que, se esta objeção coloca um problema para Kant, este não é um problema específico de sua filosofia da história, mas um problema inerente à própria ideia de que uma boa educação moral pode ser efetiva e levar os receptores a aperfeiçoar sua disposição moral. A objeção se aplicaria igualmente a qualquer comparação, por exemplo, entre dois indivíduos vivendo na Königsberg do século XVIII, um dos quais criado por um excelente pedagogo maiêutico de tendência kantiana e o outro criado em um clima de superstição religiosa e autoritarismo moral. Se, em parte, como resultado de uma boa educação, o primeiro é capaz de alcançar um caráter melhor, nós enfrentaríamos a mesmíssima questão sobre se essa "sorte" afetaria nossa avaliação comparativa.

A versão reformulada da objeção de Fackenheim não é que Kant seja inconsistente, mas que ele é injusto, o que envolve uma avaliação moral. Isto levanta a questão da perspectiva normativa a partir da qual a acusação é feita, porque a teoria moral de Kant teria que ser mostrada como incoerente somente se fosse o caso de Kant ser injusto em seus próprios termos. Se, ao contrário, o julgamento da injustiça é alcançado a partir de outras premissas que não kantianas, isto nos levaria de volta à discussão em um nível mais fundamental da teoria moral.

Dentro da estrutura da obra de Kant, contudo, não há outra opção senão aceitar a situação. Dado que Kant acredita que cada ser humano deve ter um senso basicamente correto de obrigação moral, o progresso moral significa que as gerações anteriores eram moral- 
mente inferiores, e que mais indivíduos destas gerações deixam sua vontade se determinar pelas suas inclinações do que nas gerações posteriores. Kant não pode responder (de modo consistente) à acusação de injustiça argumentando que as primeiras gerações (ou indivíduos educados por pais doutrinadores) não são completamente responsáveis pela qualidade de suas intenções. De um ponto de vista kantiano isto seria uma cura pior do que a suposta doença, porque privaria as primeiras gerações de sua personalidade moral.

Se Kant quer admitir (ainda que regulativamente) a atualidade ou a potencialidade do progresso moral, ele deve também admitir o efetivo progresso, ou falar de modo completo de nosso dever de nos esforçarmos pelo melhoramento moral em escala social. Portanto, ele não pode evitar ter que admitir a possibilidade de que as épocas anteriores eram moralmente piores. Kant vai mais além e também admite (regulativamente) que bá progresso, e ele não se esquiva de extrair daí as consequências. Ele afirma que tanto nos indivíduos quanto nas espécies o mal radical na natureza humana se manifesta no próprio uso da razão. Os humanos têm "uma propensão a desejar ativamente o ilícito, ainda que saiba que é ilícito, isto é, uma propensão para o mal, que se faz sentir tão inevitavelmente e tão cedo quanto o homem comece a fazer uso de sua liberdade ${ }^{\prime \prime 54}$. Uma vez que este mal é o resultado de uma decisão livre, os agentes são totalmente culpados. Como Kant diz no Começo Conjectural da História Humana, "a história da liberdade começa do mal" ${ }^{115}$. Constantemente ele caracteriza a história como o processo de "progressão em direção ao melhor ${ }^{\text {"56 }}$.

Porém, o quanto isto é ruim? Sem endossar a pressuposição de Kant de um progresso moral geral, gostaria de sugerir que é perfeitamente aceitável culpar as gerações anteriores por aquilo que nós, posteriores, percebemos como falhas morais - caso eles tivessem podido fazer melhor, dado o conhecimento teórico e moral disponível para eles. Não é injusto, por exemplo, culpar Kant por tratar as mulheres como seres humanos menores. Essa afirmação supõe, é claro, que ele poderia e deveria ter sabido melhor. Mas a suposição não é

54. Anth, AA 07:324 (p.219).

55. MAM AA 08:115. O mesmo é válido para qualquer indivíduo, independentemente do contexto histórico, ver RGV AA 06:39-44.

56. WA, AA 08:39; RezHerder, AA 08:65; MAM, AA 08:115; TP, AA 08:308; Anth, AA 07:324; SF, AA 07:88-9. 
implausível dado que ele explicita sua teoria moral completamente em termos do que se aplica a 'seres racionais finitos', que o status das mulheres era uma questão em debate em seus dias, que um conhecido de Kant de Könisgberg publicou um tratado feminista, e que mulheres naquele tempo confrontaram Kant sobre seus estereótipos de gênero ${ }^{57}$. Ainda que Kant possivelmente tenha enfrentado mais obstáculos culturais para atingir uma compreensão da igualdade moral de homens e mulheres do que os filósofos de hoje, isto não justifica suas concepções não-igualitárias nem tampouco exonera Kant por defendê-las.

\section{Por que Kant acredita no progresso?}

A possibilidade de progresso racional e moral é indispensável na teoria moral de Kant. Se o desenvolvimento racional fosse impossível, isto "aboliria todos os princípios práticos" ${ }^{118}$. Dever implica poder, e, assim, por exemplo, o comando para lutar para ser moralmente perfeito implica que o progresso moral é possível para os indivíduos; e porque este comando se aplica a todo ser racional finito, o progresso moral em larga escala deve ser considerado como possível.

Mas é um longo passo do "poder" para o "é", e desta forma a afirmação de Kant de que bá progresso (ainda que este tenha apenas status regulativo) não pode ser apoiada apenas na mera referência ao dever moral. Kant ocasionalmente adota tal abordagem, argumentando que, dado que devemos promover o melhoramento moral dos jovens, temos que admitir que há progresso na história ${ }^{59}$. Mas este ar-

57. O conhecido é um dos convidados regulares de Kant, o prefeito de Königsberg, Theodor Gottlieb von Hippel. Ele é autor do livro Uber die bürgerliche Verbesserung der Weiber [Sobre o melhoramento civil das mulheres] (Berlin: Voss, 1792). Os relatos sobre mulheres confrontando Kant podem ser encontrados em Stuckenberg, J. H. W. The Life of Immanuel Kant. Lanham: University Press of America, 1986 [orig.1882], p.186.

58. IaG, AA 08:19.

59. Ver a terceira parte de "Teoria e Prática". Neste ensaio Kant faz um apelo ao dever de melhorar a posteridade (por exemplo, pela educação moral, ilustração) para justificar a afirmação de que "o gênero humano [progride] para o melhor, no que respeita ao fim moral do seu ser, e que este progresso foi por vezes interrompido, mas jamais cessará". TP AA 08:308s (p.96) Kant também defende uma tese mais fraca, segundo a qual é possível que as coisas serão melhores no futuro TP AA 08:309. 
gumento é inválido. Das premissas que 1 - nós devemos promover o melhoramento moral dos jovens e que 2 - dever implicar poder, não se segue que 3 - os jovens vão melhorar moralmente, menos ainda que 4 - progresso em direção a esse fim já tenha sido feito. Como coloca Henry Allison, "ought implies can, not shall"60. O que se segue é apenas uma afirmação muito mais modesta, a saber, que o progresso deve ser visto como possível. Mas esta afirmação mais modesta não equivale a uma visão teleológica da história e, assim sendo, não dá apoio à crença de Kant no progresso.

Tampouco ele poderia sustentar esta crença argumentando que ela é necessária para que se reconheça o dever moral do indivíduo. Isto contradiria a validade incondicional do imperativo moral. Por último, tampouco poderia ele argumentar que a moralidade nos obriga a acreditar que há progresso na história. $\mathrm{O}$ imperativo categórico nos diz como nós devemos agir, não quais crenças teóricas em particular nós devemos sustentar. Astutamente, Kant se abstém de elaborar quaisquer destes dois últimos argumentos. Mas, então, como ele dá sustentação à crença no progresso?

Em seu primeiro texto sobre história, Ideia de uma História Universal, Kant desenvolve um modelo teleológico de história, com a intenção de fornecer um fio condutor para o futuro historiador. Ao final do ensaio, ele afirma que há também razões morais para adotar este modelo. Não que o caráter vinculante da moralidade dependa de nossa visão da história; se não houvesse esperança de progresso, nossa obrigação moral não deixaria de existir. Mas, nos diz Kant, nós também teríamos que desviar nossas esperanças morais deste mundo para "outro mundo". A visão teleológica da história evita este desespero mundano retratando o desenvolvimento racional e moral como viáve ${ }^{\beta 1}$. Embora ele tenha desenvolvido a ideia de história para propósitos teóricos - a saber, fornecer um guia para o futuro historiador - o

60. Allison, H. E. "The Gulf between Nature and Freedom and Nature's Guarantee of Perpetual Peace" em Proceedings of the Eight International Katn Congress, ed. Hoke Robinson. Milwaukee: Marquette University Press, 1995, p.46. Paul Guyer argumentou de modo similar sobre este ponto em "Nature, Morality and the Possibility of Peace", em Proceedings of the Eight International Kant Congress, p.66.

61. IaG, AA 08:30. 
"consolo" que ela traz ao agente moral fornece uma motivação a mais para adotar este modelo de história. ${ }^{62}$

A Crítica da Razão Prática fornece espaço lógico para este passo. Na Dialética da segunda Crítica, Kant argumenta que reconhecer nosso dever acarreta considerá-lo como possível de ser realizado ("dever implica poder"), o que por sua vez acarreta admitir a existência das condições desta possibilidade. Mas o caráter preciso destas condições está aberto a interpretações. Elas precisam envolver alguma espécie de harmonia entre os reinos da natureza e a moralidade, mas esta harmonia pode ser concebida de diferentes maneiras. Na Crítica da Razão Prática, Kant se utiliza de muitas palavras para dizer que nós temos uma "escolba" quanto ao modo de representarmos essa harmonia. ${ }^{63}$ Já que nada se pode conhecer a esse respeito, nós somos livres para representar esta harmonia do jeito que melhor servir ao interesse da moralidade. Na segunda Crítica, Kant formula essa harmonia em termos do postulado de Deus, que é dito como tendo trazido uma harmonia com finalidade entre os dois reinos. Kant concebe este Deus como um sábio "autor do mundo" 64 . Mas se nós temos uma "escolha" no assunto, parece ser permissível para Kant elaborar ainda mais essa conexão "com finalidade" entre natureza e moralidade em sua visão teleológica da história, especialmente porque ele já argumentou que esta concepção de história é teoricamente defensável. Esta elaboração envolveria a assunção de que a natureza (as disposições humanas naturais) conduz a mesma direção na qual a moralidade nos obriga a ir ${ }^{65}$.

62. IaG, AA 08:30 Kant também afirma que essa visão da história "justifica a providência", na medida em que o sofrimento que os seres humanos causam a si próprios durante a história é redimido pelo fato de que é uma parte do processo que traz a humanidade para mais perto de um bom fim. IaG, AA 08:30. Esta teodicéia histórica é altamente problemática dentro de sua filosofia moral, mas isto não afeta a questão que está em discussão neste artigo.

63. $\mathrm{KpV}$, AA 05:144-145.

64. A interpretação corrente de que o postulado de Deus serve para sustentar a crença de que os virtuosos serão recompensados em uma vida posterior ignora o fato de que Kant primeiramente descreve Deus como o criador do mundo. Cf. KpV, AA 05:126, 128, 129, 130, 145

65. Kant escreveu na margem de Para a paz perpétua "É melhor admitir que a natureza nos seres humanos trabalha para o mesmo objetivo que a moralidade". Immanuel Kant Werksausgabe, ed. Wilhelm Weischedel. Frankfurt: Suhrkamp, 1977, vol. XI, p.237, n.2. 
Deus seria assim concebido como "organizando" o mundo de tal modo que o potencial racional dos humanos possa ser completamente desenvolvido no curso da história das espécies. E esta é exatamente a concepção que Kant desenvolve na Ideia de uma História Universal.

Neste ponto, uma última objeção pode ser levantada. Embora Kant tenha êxito em evitar a dependência heterônoma da moralidade em relação à filosofia da história, isto pode ser visto como um tiro pela culatra por tirar a responsabilidade moral das mãos dos agentes. Se a história é vista como progressiva, isto não torna nosso dever supérfluo? Desde Hegel, Kant tem sido criticado por ignorar este problema ${ }^{66}$. Mas esta crítica não compreende o problema corretamente. Na visão de Kant, a habilidade para usar a razão de desenvolve gradativamente, mas este desenvolvimento não causa, ele mesmo, que os seres humanos sejam morais em um sentido determinista qualquer. Embora gerações futuras possam se beneficiar de uma educação melhorada e dos insights alcançados pelas gerações anteriores, qualquer progresso moral é o resultado de atos espontâneos da liberdade ${ }^{67}$.

\section{Conclusão}

A noção de Kant de 'desenvolvimento das disposições para o uso da razão' é compatível com aspectos-chave de sua teoria moral, mas é importante compreender o que torna esta consistência possível, a saber, uma visão pré-Darwinista da estrutura do desenvolvimento e da natureza das disposições. Defendi a noção de Kant de progresso moral e racional, inteiramente em termos de consistência e não de verdade. Kant recomenda a teoria da epigênese por seu "uso mínimo do sobrenatural'68 Mas ele ainda usa a ideia de Deus enquanto projetista da ordem teleológica. Além disto, seu modelo orgânico de 'desenvolvimento' se tornou obsoleto. Uma teoria kantiana da moral, atual, não pode mais tirar vantagem da teoria biológica do modo como Kant o fez.

66. Hegel, G. W. F. Fenomenologia do Espírito. Tradução de Paulo Meneses. Petrópolis: Editora Vozes, 2003, §§ 599-631.

67. Ver também Allison, H. E. "The Gulf Between Freedom and Nature", p.47. À luz dessa fina análise, é um tanto estranho que Allison ainda sustente que a ligação entre finalidade na história e o propósito final da criação (um mundo moral) seja obscuro (p.42).

68. KU, AA 05:424. 
Mas o propósito deste artigo é mostrar que a teoria moral de Kant deixa espaço para a noção de progresso moral, o que é uma questão que precede logicamente quaisquer tentativas de melhorar as concepções de Kant da possibilidade ou efetividade do progresso moral. Que haja espaço para o progresso é vital para as teorias morais de Kant e dos kantianos. Ainda que se desista da crença num progresso moral efetivo, a possibilidade de melhoramento moral precisa ser consistente em um nível conceitual, e essa possibilidade deve ser considerada, caso contrá rio as exigências da moralidade são irracionais. Se deve ser possível para a teoria moral kantiana apresentar uma descrição de como as exigências morais podem ser realizadas no mundo, e como a ação moral livre pode mudar o mundo para melhor, deve haver espaço dentro da estrutura kantiana para que a ideia de que capacidades racionais possam se desenvolver e que a conduta moral pode melhorar com o tempo.

\section{Tradução de Cauê Cardoso Polla}

Abreviações das obras kantianas elencadas na Akademie Ausgabe (AA), e suas respectivas traduções, quando disponíveis.

Anth - Anthropologie in pragmatischer Hinsicht (AA 07)

Antropologia de um ponto de vista pragmático. Tradução de Clélia Aparecida Martins. São Paulo: Iluminuras, 2006.

BBMR - Bestimmung des Begriffs einer Menschenrace (AA 08)

EAD - Das Ende aller Dinge (AA 08)

O fim de todas as coisas. In: A Paz Perpétua e outros Opúsculos. Tradução de Artur Mourão. Lisboa: Edições 70, 2004, 103-119.

GMS - Grundlegung zur Metaphysik der Sitten (AA 04)

Fundamentação da Metafísica dos Costumes. Tradução de Paulo Quintela. Lisboa: Edições 70, s/d.

$\mathrm{IaG}$ - Idee zu einer allgemeinen Geschichte in weltbürgerlicher Absicbt (AA 08)

Idéia de uma História Universal de um Ponto de Vista Cosmopolita. Tradução de Rodrigo Naves e Ricardo Ribeiro Terra. São Paulo: Martins Fontes, 2003.

$\mathrm{KpV}$ - Kritik der praktischen Vernunft (AA 05)

Crítica da Razão Prática. Tradução de Valério Rohden. São Paulo: Martins Fontes, 2002.

$\mathrm{KrV}-$ Kritik der reinen Vernunft (A/B) 
Crítica da Razão Pura. Tradução de Fernando Costa Mattos.

Petrópolis: Vozes, 2012.

KU - Kritik der Urteilskraft (AA 05)

Crítica da Faculdade do Juízo. Tradução e notas de António Marques

e Valério Rohden. São Paulo: Forense Universitária, 2012.

MAM - Mutbmaßlicher Anfang der Menschengeschichte (AA 08)

Começo Conjectural da História Humana in: Cadernos de Filosofia Alemã.

Tradução de Bruno Nadai, Jan-Jun, 2009, São Paulo. Publicação

Semestral do Departamento de Filosofia - FFLCH/USP, 109-124

Päd - Pädagogik (AA 09)

RezHerder - Recensionen von J. G. Herders Ideen zur Philosophie der Geschichte der Menscheit (AA 08)

RGV - Die Religion innerhalb der Grenzen der bloßen Vernunft (AA 06) Religião nos Limites da Mera Razão. Tradução de Artur Mourão. Lisboa: Edições 70, 2008.

SF - Der Streit der Fakultäten (AA 07)

TP - Über den Gemeinspruch: Das mag in der Theorie richtig sein, taugt aber nicht für die Praxis (AA 08)

Sobre a expressão corrente: isto pode ser correto na teoria, mas nada vale na prática. In: A Paz Perpétua e outros Opúsculos. Tradução de Artur Mourão. Lisboa: Edições 70, 2004, 57-102.

ÜGTP - Über den Gebrauch teleologischer Principien in der Philosophie (AA 08)

WA - Beantwortung der Frage: Was ist Aufklärung? (AA 08)

Resposta à pergunta: que é iluminismo? 11-20. In: A Paz Perpétua e outros

Opúsculos. Tradução de Artur Mourão. Lisboa: Edições 70, 2004, 11-20.

WDO - Was heißt sich im Denken orientiren? (AA 08)

Que significa orientar-se no pensamento? In: A Paz Perpétua e outros Opúsculos. Tradução de Artur Mourão. Lisboa: Edições 70, 2004, 37-56

$\mathrm{ZeF}-\mathrm{Zum}$ ewigen Frieden (AA 08)

A Paz Perpétua. In: A Paz Perpétua e outros Opúsculos. Tradução de Artur Mourão. Lisboa: Edições 70, 2004 ,119-172

\section{Bibliografia secundária:}

ALLISON, H. E. "The Gulf between Nature and Freedom and Nature's Guarantee of Perpetual Peace" in: Proceedings of the Eight International Kant Congress, ed. Hoke Robinson (Milwaukee: Marquette University Press, 1995), 37-49 
ANDERSON-Gold, S. "Kant's Ethical Commonwealth: The Highest Good as a Social Goal", International Pbilosopbical Quarterly 26 (1986): 23-32

DESPLAND, Michael. Kant on History and Religion. Montreal: Mc GillQueen's University Press, 1973

FACKENHEIM, E. L. "Kant's Concept of History", Kant-Studien 48 (1956-57): $381-398$

GALSTON, W. A. Kant and the Problem of History. Chicago: University of Chicago Press, 1975

GUYER, P. "Nature, Morality and the Possibility of Peace", in: Proceedings of the Eight International Kant Congress, ed. Hoke Robinson (Milwaukee: Marquette University Press, 1995) p.51-69

HEGEL, G. W. F. Fenomenologia do Espírito. Tradução de Paulo Meneses, Petrópolis: Editora Vozes, 2003

HÖFFE, O. Immanuel Kant. München: Beck, 1983. [Höffe, Otfried Immanuel Kant. Tradução de Christian Hamm e Valério Rohden. São Paulo: Martins Fontes, 2005]

KLEINGELD, P "The Problematic Status of Gender-Neutral Language in the History of Philosophy: The Case of Kant", Pbilosopbical Forum 25 (1993): 134-150

Fortschritt und Vernunft: Zur Gescbicbtspbilosopbie Kants. Würzburg: Königshausen und Neumann, 1995

KORSGAARD, C. Creating the Kingdom of Ends. Cambridge: Cambridge University Press, 1996

MACLAUGHLIN, P. Kants Kritik der teleologischen Urteilskraft. Bonn: Bouvier, 1989

REATH, A. "Two Conceptions of the Highest Good in Kant", Journal of the History of Pbilosopby 26 (1988):593-619

STERN, P. "The Problem of History and Temporality in Kantian Ethics" in: Review of Metapbysics 39 (1986): 505-545

STUCKENBERG, J. H. W. The Life of Immanuel Kant (Lanham: University Press of America, 1986 [orig. 1882])

VON HIPPEL, T. G. Uber die bürgerliche Verbesserung der Weiber Berlin: Voss, 1792.

WOOD, A. W. "Unsocial Sociability: The Anthropological Basis of Kantian Ethics", Pbilosopbical Topics 19 (1991): 325-351

YOVEL, Y. Kant and the Pbilosopby. Princeton: Princeton University Press, 1980

ZAMMITO, J. H. The Genesis of Kant's "Critique of Judgment. Chicago: University of Chicago Press, 1992 